\title{
A PARSIMONIOUS MODEL FOR THE SAFETY ASSESSMENT OF HORIZONTAL CURVES USING DATA FROM RURAL ROADS
}

\author{
E. MATSOUKIS \\ Transportation \& Traffic Engineering Unit, Department of Civil Engineering, \\ University of Patras, Greece.
}

\begin{abstract}
The safety of a horizontal curve (by means of accident frequency and degree of severity) is examined in this paper by features internal and external to it; both of these characteristics affect the driver attitude and the curve approach speed. Based on a review of the available literature on the subject, first the relationship between accident rate and some of the most important curve characteristics is examined. Then data from rural highways in Greece are used to investigate the relationship between accident rate and degree of curve or the curve radius. The flexible family of Gamma distributions is selected for this analysis and models using a special form of it (the shifted negative exponential distribution) are defined. The estimated functional forms are presented in conjunction with those from the literature and conclusions are drawn.
\end{abstract}

Keywords: Horizontal alignment, horizontal curves safety, road geometric characteristics, rural roads.

\section{INTRODUCTION}

Highway engineering includes an explicit trade-off between the improvement of the speed and throughput of highways and maintaining safe operating levels. The safe and efficient movement of traffic is greatly influenced by the geometric features of the highway. Accident trend analyses often lead to the observation that accidents tend to cluster in specific spots, including intersections and curves. Understanding the reasons that determine the safety level is instrumental in improving road safety.

There are several elements of horizontal alignment that are associated with horizontal curve safety. The safety of a horizontal curve - its accident frequency and severity - is partly determined by features internal to it (radius or degree of curve, superelevation, spiral, etc.) and partly by features external to it (density of curves upstream, length of the connecting tangent sections, sight distance, etc.) that influence driver expectation and curve approach speed.

In this paper, the internal features are investigated, and more specifically the relationship between accident rate and degree of curve or the curve radius. The contribution of this paper includes the investigation of the model form that can be applied to the Greek road safety environment. Furthermore, the examination of different functional forms for the estimated curve resulted in selecting the family of gamma distributions and, in particular, the shifted negative exponential distribution. This family of distributions presents interesting statistical properties and it should be further investigated with other data sets.

\section{REVIEW}

The relationship between the degree of curve and the accident occurrence on the curve has long been accepted and investigated. Lamm et al. [1] present an overview of the relationship between accident rate and radius of curve, as derived from the results of several research studies. 
More than half a century ago, Raff [2] examined how accident rates depend on the design features of main rural roads using data from about 5000 miles of highway from 15 states in the USA. The relationship between the accident rate and the degree of curve for four road types is summarized in Fig. 1 (in which U stands for 'undivided', D for 'divided', and CA for 'controlled access'). Raff calculated the following linear relationship based on these data:

$$
\text { accidents } / M V M=1.3+0.25 D \text { or accidents } / M V k m=0.8+0.16 D
$$

where $M V M$ is the million vehicles per mile, $M V k m$ is the million vehicles per $\mathrm{km}$, and $D$ is the degree of curve. In Fig. 2 the relationship of accident rate versus radius of curve is shown.

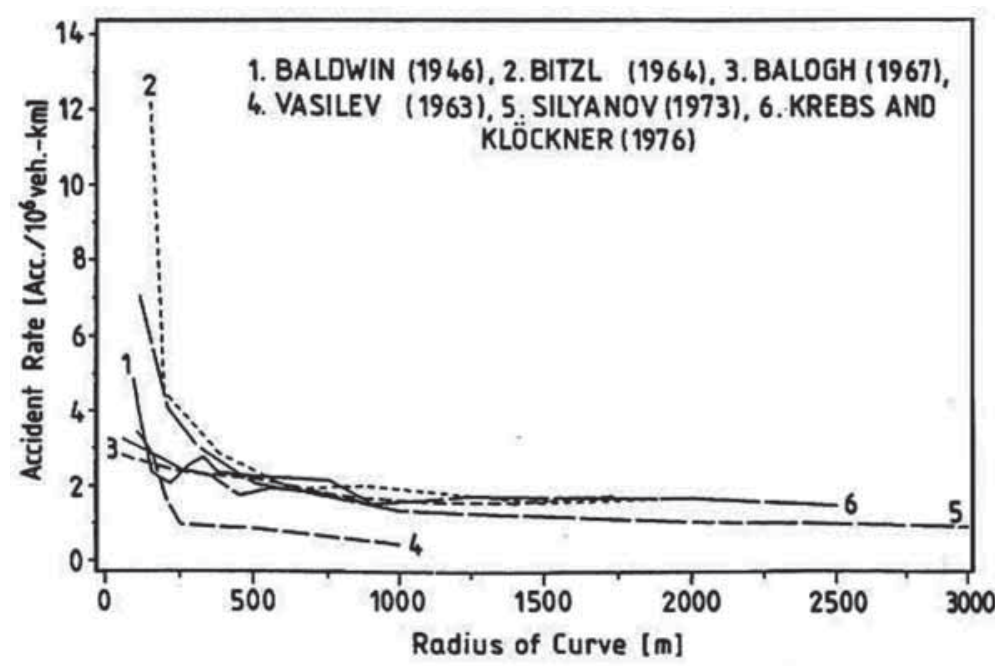

Figure 1: Accident rate versus degree of curve [2].

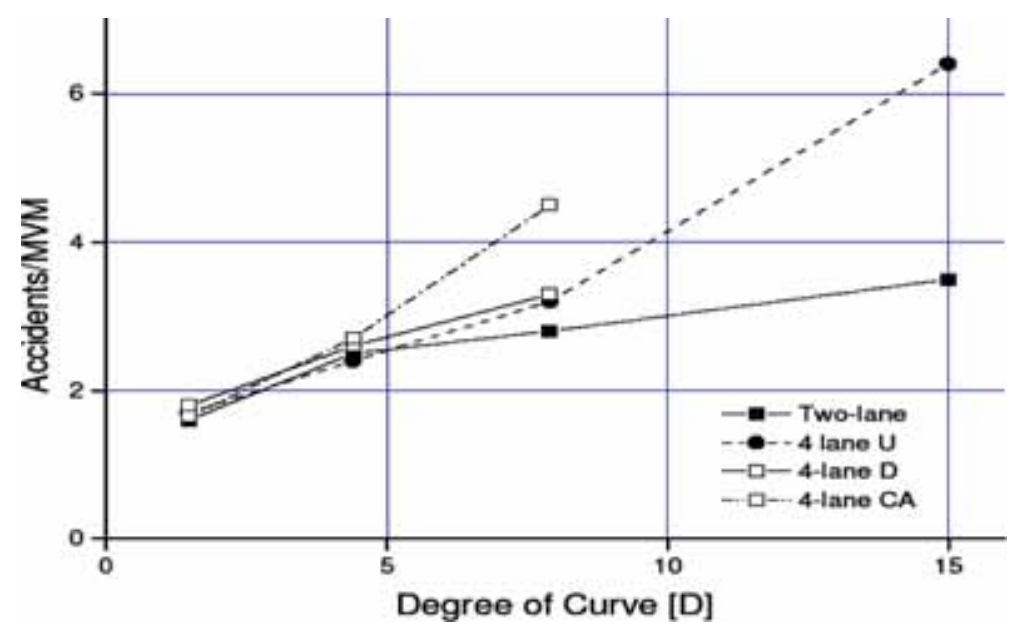

Figure 2: Visualization of relationships of accident rate versus radius of curve (source: Lamm et al. [1]). 
One of the early comprehensive reviews of empirical findings on the relation of horizontal curvature and accident risk is by Leisch et al. [3]. Figures 3 and 4 are based on the extrapolation of five old studies. The same data points are used in both figures, except that one shows the degree of the curve on the horizontal axis and the other shows the curve radius. This exposition highlights some interesting characteristics of the different measures of the curve geometry. In particular, while it seems that the relationship between the degree of curve and the accident risk is roughly linear, the relationship between the radius of the curve and the

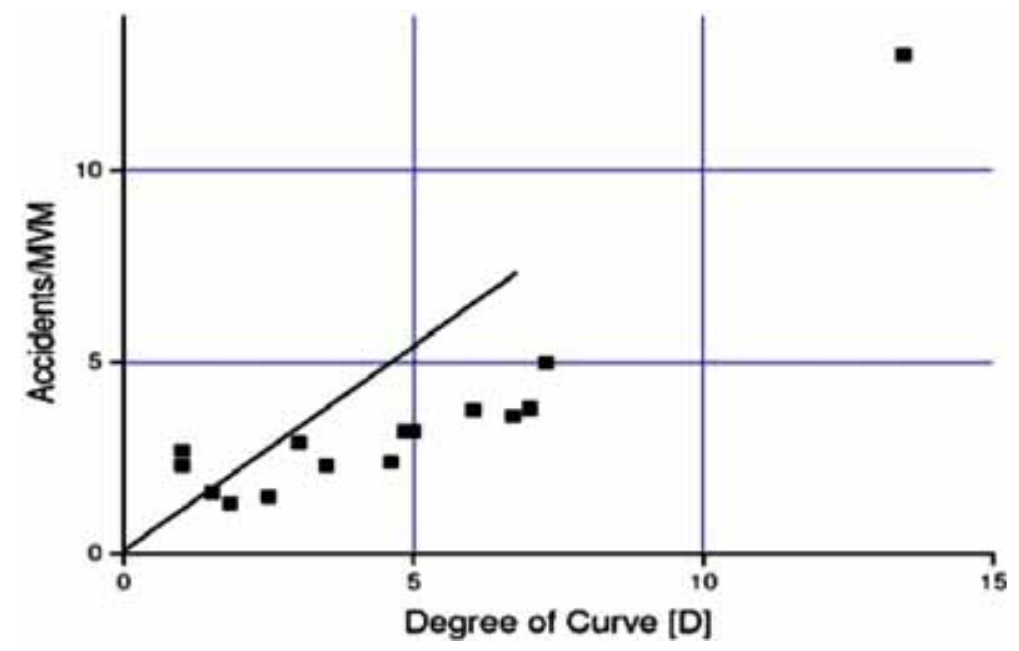

Figure 3: Accident rate versus degree of curve [3].

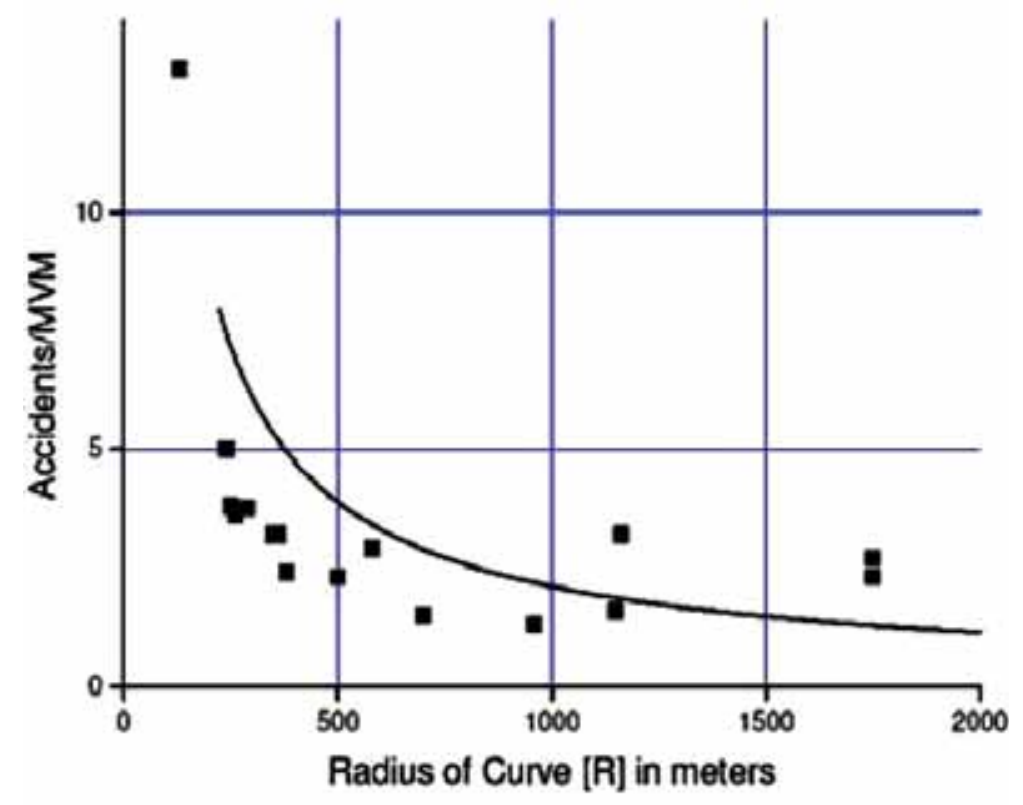

Figure 4: Accident rate versus curve radius [3]. 
accident risk is clearly nonlinear. The shape of the relation between the radius of the curve and the accident risk implies that an increase of, e.g. $100 \mathrm{~m}$ in radius has a higher road safety impact when the radius of the curve is smaller. This could, however, be misinterpreted to mean that there are no real benefits in increasing the radius of the curve above a certain value. It is noted that this type of analysis looks only at the internal elements of the curve and ignores its external characteristics, such as the sequence of preceding curves. Like the study of Raff [2] and many other studies in the field, the data used in this analysis come from an inhomogeneous group of road segments. In spite of this observation, there seems to be a large measure of congruence in the empirical findings. The authors fit the following relationship for the relation of the accident rate with the degree of curve:

$$
\text { accidents } / M V M=1.8+0.34 \mathrm{D}
$$

Matthews and Barnes [4] used data from New Zealand to explore the relationship between accident rate and radius of curvature. Based on geometry data for 4666 curves from State Highways 1 and 5 years of accidents (total of 1082), the authors fit the following relationships:

$$
\text { accidents } / \mathrm{MVkm}=8.5 / R^{0.64}=0.071 \times D^{0.64}
$$

These relationships are shown in Figs 5 and 6.

Deacon [5] analyzed road accident risk data for a data set, which consisted of 351 straight and 3297 curved road segments. Each road segment was 1-km long. Curved road segments consisted of a curve and at least $200 \mathrm{~m}$ of tangent on each side. Table 1 summarizes some of the data. From an overview of these data, one can deduce that sharper curves tend to have narrower lanes and shoulders. One may surmise that the degree of curve is associated with other road features as well. Thus, one may expect longer curves in level terrain to be associated with small degrees and vice versa. Therefore, a part of the increase in accident rate that is evident in column 2 may also reflect the influence of these correlated variables. After some data manipulation, Deacon reached the following function:

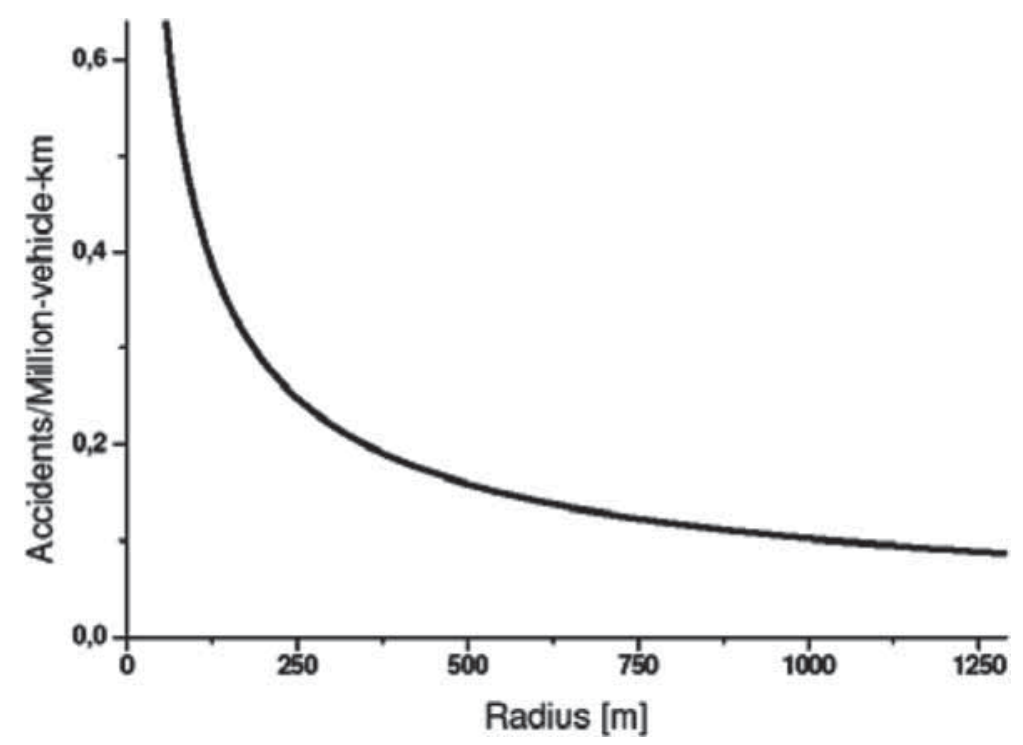

Figure 5: Accident rate versus curve radius. Matthews and Barnes research [4]. 


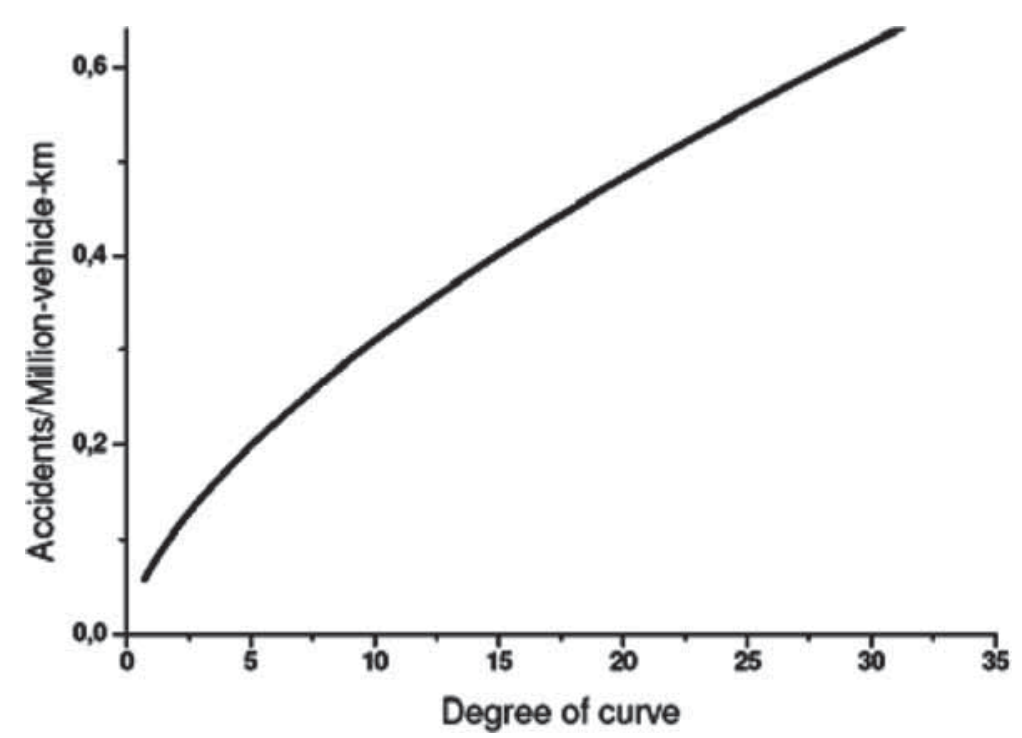

Figure 6: Accident rate versus degree of curve [4].

$$
A=(r \times L+0.0336 \times D) \times V
$$

In this, $A$ is the number of curve accidents, $r$ is the accident rate (accidents per million vehicle miles) on a straight road segment, $L$ is the curve length in miles, $V$ is the number of vehicles (in millions), and $D$ is the degree of curve.

Deacon's model is conceptually different from the previous models, as it implies that the increase in accidents on a curve $(0.0336 \mathrm{DV})$ is due to the mere existence of the curve of

Table 1: Summary of data from Deacon [5].

\begin{tabular}{lcccc}
\hline Degree of curve & Accidents/MVM & ADT & Average lane width (ft) & Shoulder width (ft) \\
\hline 0 & 0.90 & 3400 & 11.5 & 7.2 \\
$0.01-0.74$ & 1.38 & 3100 & 11.7 & 7.7 \\
$0.75-1.49$ & 1.06 & 3300 & 11.9 & 7.5 \\
$1.50-2.49$ & 1.24 & 3200 & 11.8 & 7.4 \\
$2.50-3.49$ & 1.61 & 3400 & 11.7 & 7.3 \\
$3.50-4.49$ & 2.41 & 3000 & 11.3 & 6.3 \\
$4.50-6.49$ & 2.79 & 3200 & 10.9 & 5.9 \\
$6.50-8.49$ & 2.89 & 3300 & 10.4 & 4.8 \\
$8.50-10.5$ & 3.59 & 3000 & 10.2 & 4.8 \\
$10.5-12.5$ & 4.03 & 3200 & 10.3 & 4.8 \\
$>12.5$ & 4.19 & 2900 & 10.0 & 4.8 \\
\hline
\end{tabular}

Lamm et al. [6] used data from 261 road sections (from two-lane rural roads) and 3 years of accident data (a total of 815 accidents) to develop a linear regression model: 
degree $D$ and does not depend on the length of the curve. In such an approach, the curve is implicitly considered a 'point-risk' (akin to an intersection or narrow bridge) so that, if the driver manages the difficulty of changing from the straight to the curved section or changing back from the curve into the straight section, the remaining driving along the curve is just like any straight road.

$$
\text { accidents } / M V M=-0.88+1.41 D \text { for } 1^{\circ}<D<6.9^{\circ}
$$

The authors note that the 'degree of curve was found to be the best single variable predictor available. The other variables helped the regression model but the equation did very well even without them'.

Zegeer et al. [7] present a study using a very broad database consisting of 10,900 horizontal curves in Washington State, including traffic, accident, and geometric characteristics of each curve. Based on the analysis of the data, the authors adopted the following model:

$$
A=(1.552 L+0.014 D-0.012 S) \times V \times 0.978^{W-30}
$$

where $A$ is the number of accidents/year; $L$ is the length of curve in miles; $D$ is the degree of curve; $S=1$ if spirals exist and 0 otherwise; $V$ is the volume of vehicles/year in millions (for both directions of traffic); $W$ is the 'roadway width in feet', i.e. the total width of all lanes and shoulders. The functional form of eqn (6) is similar to that used by Deacon [5] and has been adopted mainly because 'the interaction of traffic and roadway variables are reasonable and make sense in terms of accident occurrence on curves'.

Voigt A. [8] used data from 247 curves on two-lane rural roads in Texas and 7 years of accident data and estimated that

$$
\text { accidents } / M V M=0.102 \times e^{0.0064 D-0.1}
$$

This relationship is visually represented in Fig. 7.

In [9], Anderson et al. examine the relationship of safety to five candidate measures of geometric design consistency for rural two-lane highway alignments. The measures that were evaluated included: $(a)$ speed reduction on a horizontal curve relative to the preceding tangent or curve, $(b)$ average radius, $(c)$ ratio of maximum radius to minimum radius, $(d)$ average rate of vertical curvature, and $(e)$ ratio of individual curve radius to average radius. All of these measures were found to have statistically significant relationships to accident frequency.
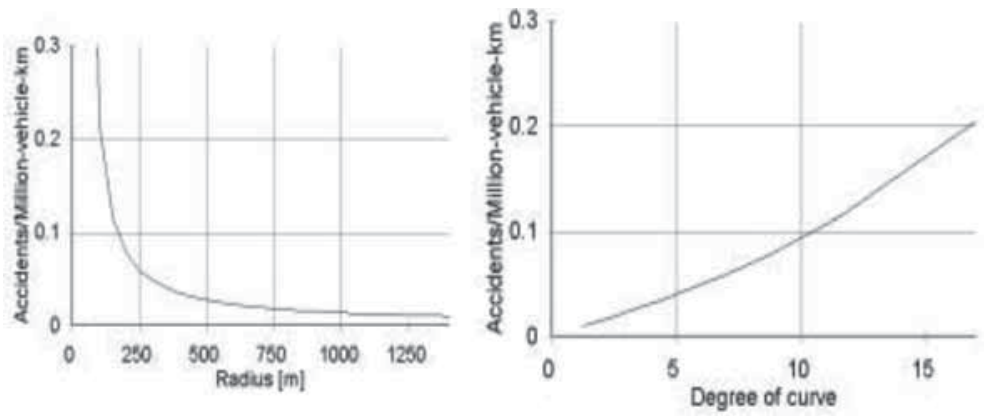

Figure 7: Accident rate versus radius or degree of curve [8]. 
Zhang Chen and Ivan [10] use negative binomial generalized linear models to evaluate the effects of roadway geometric features on the incidence of head-on crashes on two-lane rural roads in Connecticut. Variables found to influence the incidence of head-on crashes significantly were speed limit, sum of absolute change rate of horizontal curvature, maximum degree of horizontal curve, and sum of absolute change rate of vertical curvature.

Aram [11] found, among others, that significant factors that affect safety are the degree horizontal curve, total length segment of horizontal curve, and length spiral curve.

While research is continually growing in this subject, some conclusions of the above literature review can be drawn: (i) in several studies, the accident rate increases approximately linearly with the degree of curve. Since the radius is proportional to the reciprocal value of the degree of curve, the accident rate diminishes approximately hyperbolically with curve radius. (ii) The tendency of the accident rate to increase as the degree of curve increases is present not only on two-lane rural roads but also on multilane roads and access controlled roads in urban and rural environments. (iii) There are a few studies that did not find the tendency for accident rates to increase with the degree of curve. In some studies, the increase was not linear.

\section{ACCIDENT AND GEOMETRIC CHARACTERISTICS' DATA COLLECTION}

For an investigation of the relation between the geometric characteristics of a (rural) road and the accident rate, data of the geometric characteristics, the accidents, and traffic volumes are necessary. For the purposes of this research, the data were collected from various rural road sections, with the characterization 'National Road' in the Greek Continental Area [12]. Specifically, this was collected from:

- The Athens-Korinth-Patras New National Road: section from Korinth to Patras (total length $108 \mathrm{~km})$.

- The Antirrion-Mesologgi-Arta National Road: section from Antirrion to Amfilochia (total length $119 \mathrm{~km})$.

\subsection{Accident data}

Accident data used came from the database of the NTUA (National Technical University of Athens, Civil Engineering Department and Sector of Transport).

The data referred to years 2001 until 2009, and for each accident they included: year, date, $\mathrm{km}$ location where the accident took place, and information on whether the relevant road section was tangent, included a right turn, included a left turn, or had a pair of two adjacent curves.

\subsection{Geometric characteristics}

The geometric characteristics of the road sections taken into consideration came also from NTUA. These included, as far as the horizontal alignment is concerned, the following:

- Radius of curve.

- Parameters of the spirals' entry and exit points.

- Width of traffic lanes.

For each section under study, the kilometer locations of the entry and exit points were known. Also, for each section, the coordinates of entry and exit points were known. 


\subsection{Traffic volumes}

The data of traffic volumes for the road sections under investigation came from the files of the toll authorities of the Greek National Roads; also, from files of the Greek Ministry of the Environment, Land Planning and Public Roads.

\section{DATA ANALYSIS AND EVALUATION}

At a first stage, section identification was carried out by the use of a relevant road planning program on a horizontal alignment plan, and on the basis of the coordinates of the entry and exit point of each section [13]. At a second stage, from the total of road sections, those that included curves were chosen. For these sections, the road accidents that had occurred there were allocated. For each accident of this kind, the kilometer location where this took place was also known.

For each horizontal alignment curve, its length was then calculated. The corresponding traffic volume and number of accidents (for the time period 2001-2009) was also known. Therefore, it was possible to calculate the accident rate for each curve by using the following equation:

$$
R_{s}=\frac{A \times 10^{6}}{T V L}
$$

where

$R_{s}$ is the accident rate $/ M V k m, A$ is the accidents recorded in $T$ days, $T$ is the time period of accident recording (here, 365 days), $V$ is the average daily traffic for the section under study (veh/day), and $L$ is the length of the section under study in $\mathrm{km} . \mathrm{s}$

The final form of data consists of the pairs of accident rates for each curve and curve radii (or the degrees of curves).

\subsection{Curves in the section Korinth-Patras}

For the section Korinth-Patras, 138 curves were examined. The range of radii was between 350 and $1720 \mathrm{~m}$. The degree of curves $(D)$ ranged between $5 \% 100 \mathrm{ft}$ and $1 \% 100 \mathrm{ft}$, respectively. An effort to adjust various statistical distributions (linear, exponential, etc.) was made for the pairs radius $(R)$-accident rate $\left(R_{s}\right)$ and degree of curve $(D)$-accident rate $\left(R_{s}\right)$.

The results of the last statistical analysis gave the following relations:

$$
\begin{gathered}
R_{s}=0.3+3.25 \cdot e^{-\frac{R-350}{30}} \\
R_{s}=0.3+0.0002 \cdot e^{2.388 \cdot D}
\end{gathered}
$$

The correlation factors for both eqns (9) and (10) were 0.90 .

4.2 Curves in the section Antirrion-Amfilochia

For the section Antirrion-Amfilochia, 138 curves were examined. The range of radii was between $110 \mathrm{~m}$ and $3000 \mathrm{~m}$. The degree of curves $(D)$ ranged between $16^{\circ} / 100$ and $0.5^{\circ} / 100$ $\mathrm{ft}$, respectively. 
The results of the statistical analysis gave the following relations:

$$
\begin{gathered}
R_{s}=0.3+3.25 \cdot e^{-\frac{R-350}{30}} \\
R_{s}=0.3+0.0002 \cdot e^{2.388 \cdot D}
\end{gathered}
$$

The correlation factors for both eqns (11) and (12) were 0.85 .

Figure 8 presents the data and the curves that were fit by the model.

For the diagrams of Fig. $8 \mathrm{a}$ and c, which give the relationship of accident rate-curve radius, the above eqns (9) and (11) were adjusted and gave the best outcome. This belongs to the category of shifted exponential distribution. The shift refers to the horizontal axis $(R)$ and is given by the expression $R-R_{0}$. In any case, the value of $R_{0}$ depends mainly on the least radius of the sample data.

This value is obviously directly related to the category of the road under investigation. For example, for the Korinth-Patras road, the minimum radius is $350 \mathrm{~m}$ while for the AntirrionAmfilochia road it is $90 \mathrm{~m}$.

The shifted exponential distribution belongs to the family of the gamma distributions. Gamma distribution, with parameters $\alpha$ and $\beta$, is defined by the following probability density equation:
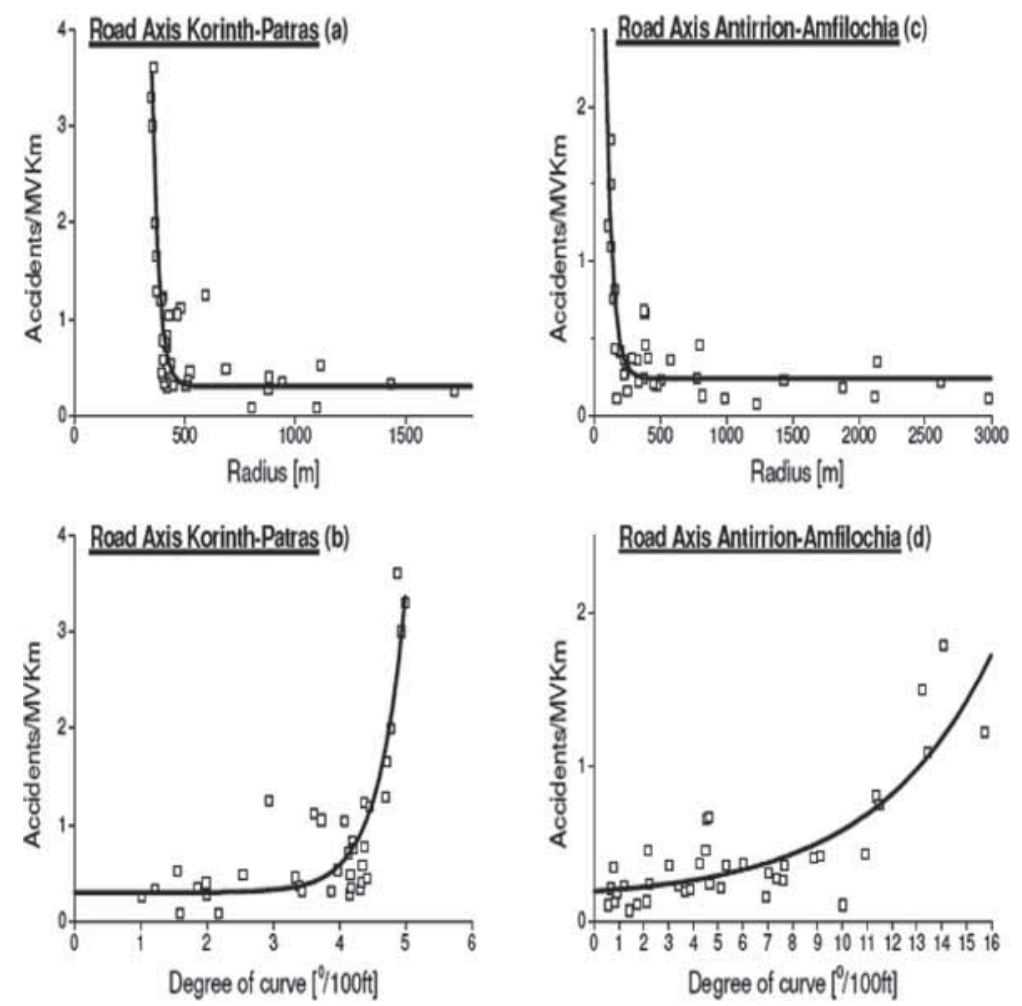

Figure 8: Accident rate versus radius or degree of curve. Graphical representation of eqns (9)-(12) (correspondingly subfigures: a, b, c, d). 


$$
p(x)=\frac{1}{\beta^{a+1} \Gamma(a+1)} x^{a} e^{-x / \beta}
$$

for $x, \alpha, \beta>0$, where $\Gamma$ is a value of the gamma distribution:

The graphical representation of the gamma distribution for the various parameters is presented in Fig. 9.

In Fig. 9 for $\alpha=0$, the form of the graphical representation looks like that of the data of the relation accident rate-curve radius. Given the flexibility of the gamma distribution, an application of this gamma distribution to this problem may give superior results.

\section{CONCLUSIONS}

Table 2 summarizes some of the relationships of accident rate with the degree and radius of curve as they are found in the literature and juxtaposes them with the findings of this research.

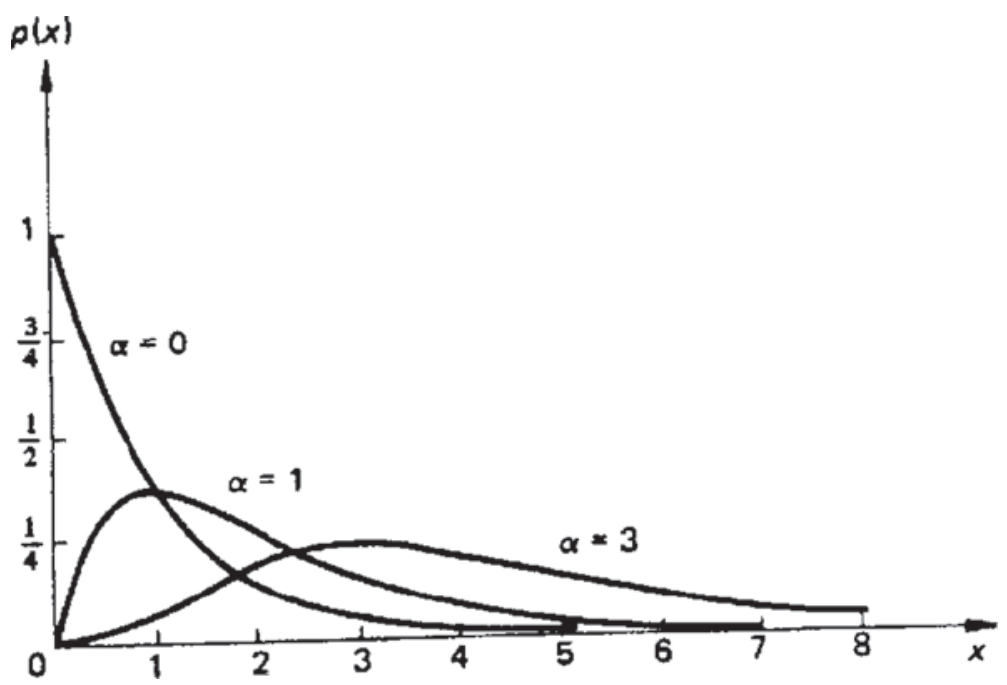

Figure 9: Graphical representations of the gamma distribution for $b=1$.

Table 2: Presentation of indicative accident rate relationships with curve degree and curve radius.

\begin{tabular}{llll}
\hline & $D$ : Degree of curve & $R$ : Curve radius & Source \\
\hline (1) $\mathrm{AR}=$ & $0.8+0.16 \mathrm{D}$ & $0.8+279.6 / \mathrm{R}$ & Raff, 1953 [2] \\
(2) $\mathrm{AR}=$ & $1.12+0.21 \mathrm{D}$ & $1.12+367 / \mathrm{R}$ & Leisch, 1971 [3] \\
(3) $\mathrm{AR}=$ & $0.071 \mathrm{D}$ & $8.5 / \mathrm{R}^{0.64}$ & Matthews and Barnes, 1988 [4] \\
(4) $\mathrm{AR}=$ & $-0.55+0.88 \mathrm{D}$ & $-0.55+1538 / \mathrm{R}$ & Lamm et al. 1988 [6] \\
(5) $\mathrm{AR}=$ & $0.14+0.055 e^{0.21 \mathrm{D}}$ & $0.24+1.62 e^{-(\mathrm{R}-100) / 50}$ & Curves from \\
(6) $\mathrm{AR}=$ & $0.3+0.0002 e^{2.39 \mathrm{D}}$ & $0.48+3.10 e^{-(\mathrm{R}-350) / 25}$ & $\begin{array}{l}\text { Antirrion-Amfilochia, 2009 } \\
\text { Curves from Korinth-Patras, 2009 }\end{array}$ \\
\hline
\end{tabular}


There are clear differences among these relationships, which may be attributed to a number of reasons, including:

- Evolution of vehicles and driving patterns (considering that the data cover several decades).

- Country of data origin (US, Australia, Greece).

- Specific characteristics of the road and crash data considered.

An expansion of the presented work that will consider explicitly the types of data and crashes and provide more detailed models could be helpful in designing road safety strategies. Data limitations are a big hindrance to such efforts, especially in countries with less organized reporting practices.

The conclusions of the present study for the rural roads are the following:

- The number of accidents diminishes with the increase in the curve radius, in a form that, in general, is that of a negative exponential distribution. Also, since the curve radius is analogous to the reciprocal of the degree of the curve, the number of accidents increases exponentially with the degree of the curve.

- The curve that fits best is that of the shifted negative exponential distribution. The reason for the existence of a 'shift' is simply that there are no data on small size curve radii. Such radii, under a certain low value, are not in use for the roads under consideration.

- To properly identify the 'shift', this latter value must be included in the calculations as a parameter. In this case, a gamma distribution should be used, to incorporate this extra parameter.

- Around the value of $R=500$, there seems to be a bend or 'knee' in the relationship between accident rate and radius. This conclusion coincides with the relevant findings of the other research efforts in this area.

- It is obvious that the features external to a curve (density of curve upstream, length of the connecting tangent sections, sight distance, etc.) that influence driver expectation and curve approach speed must also be included when examining the horizontal curve's safety. This is left for further research.

\section{REFERENCES}

[1] Lamm, R., Psarianos, B. \& Mailaender, T., Highway Design and Traffic Safety Engineering Handbook, McGraw - Hill Handbooks: NY (USA), 1999.

[2] Raff, M.S., Interstate Highway-Accident Study, Highway Research Board Bulletin 74, Traffic Accident Studies: Washington D.C., pp. 18-45, 1953.

[3] Leisch, J.E. \& Associates. Traffic control and roadway elements - their relationship to highway safety/revised. Chapter 12, Alignments. Highway Users federation for Safety and Mobility, 1971.

[4] Matthews, L.R. \& Barnes, J.W., Relation between road environment and curve accidents. Proceedings, 14th ARRB Conference, Part 4, pp. 105-120, 1988.

[5] Deacon, J., Relationship between Accidents and Horizontal Curvature, Appendix D in Designing safer roads. Special Report 214, Transportation Research Board: Washington, D.C., 1986.

[6] Lamm, R., Choueiri, E.M. \& Mailaender, T., Accident rates on curves as influenced by highway design elements - an international review and an in-depth study. Proceedings, Road safety in Europe, VTI Rapport 344A. VTI, Linkoping: Sweden, 1988. 
[7] Zegeer, C.V., Stewart, R.J., Council, F.M., Reinfurt, D.W. \& Hamilton, E. Safety Effects of Geometric Improvements on Horizontal Curves, Transportation Research Record 1356, Transportation Research Board: Washington D.C., 1992.

[8] Voigt, A., An Evaluation of Alternative Horizontal Curve Design Approaches for Rural Two-Lane Highways. Report No. TTI-04690-3, Texas Transport Institute: Dallas (USA), 1995.

[9] Anderson, I.B., Bauer, K.M., Harwood, D.W. \& Fitzpatrick, K. Relationship to Safety of Geometric Design Consistency Measures for Rural Two-Lane Highways Transportation Research Board of the National Academies 0361-1981 Volume 1658, 1999.

[10] Zhang, C. \& Ivan, J.N., Effects of Geometric Characteristics on Head-On Crash Incidence on Two-Lane Roads in Connecticut Transportation Research Board of the National Academies 0361-1981 Volume 1908, 2005.

[11] Aram, A., Effective safety factors on horizontal curves of two-lane highways. Journal of Applied Science, 10, pp. 2814-2822, 2010. doi: http://dx.doi.org/10.3923/jas. 2010.2814.2822

[12] Matsoukis, E. \& Baladimas, D., Relating road safety and geometric characteristics at horizontal curves. The case of rural roads. Proceedings of the 3rd Panhellenic Conference, Patras, Greece, October 2005.

[13] Baladimas, D., Safety Characteristics of Horizontal Curves, M.Sc. thesis, Department of Civil Engineering, University of Patras, Patras, Greece, 2009.

This paper has been selected for this special issue but first appeared in WIT Transactions on the Built Environment, Vol 117, ( $) 2011$ WIT Press, www.witpress.com, ISSN 1743-3509 (on-line), doi:10.2495/SAFE110041. 